\title{
COMPORTAMENTO DA MATURAÇÃO DE MAMÃO TAINUNG 1 CULTIVADO EM BRASÍLIA-DF ${ }^{1}$
}

\author{
OSVALDO KIYOSHI YAMANISHI², GENI RODRIGUES FAGUNDES ${ }^{3}$, JOSÉ ALTINO MACHADO FILHO ${ }^{3}$, \\ JALES VIANA FALCÃO ${ }^{4}$, SIMONE DE PAULA MIRANDA ${ }^{4}$
}

\begin{abstract}
RESUMO- Avaliou-se o comportamento da maturação de frutos de mamão Tainung 1 colhidos em diferentes estádios de desenvolvimento por meio de análises físico-químicas e determinação do teor de clorofila da casca dos frutos. Os frutos analisados tiveram teores de clorofila $a$ e $b$ semelhantes, havendo diferença apenas no intervalo do $63^{\circ}$ ao $84^{\circ}$ dia após a frutificação efetiva (DAFE). Os frutos colhidos aos 63 DAFE já apresentavam peso adequado para a colheita, porém houve aumento de peso até o $147^{\circ} \mathrm{DAFE}$. O comprimento aumentou até o $147^{\circ} \mathrm{DAFE}$, e o diâmetro estabilizou-se no $126^{\circ}$ DAFE. Os teores de sólidos solúveis totais (SST) oscilaram de 2,2 a $10,3^{\circ}$ Brix, e a acidez titulável total (ATT) variou de 0,038 a $0,077 \%$ de ácido cítrico. Os teores de clorofila $a$ e $b$ decresceram com o aumento do grau de maturação, sendo que o ponto de colheita mais indicado seria a partir do $126^{\circ}$ DAFE, onde as características físicas e os teores de SST atingiram valores adequados para colheita.
\end{abstract}

Termos para indexação: mamão, maturação, clorofila.

\section{RIPENING BEHAVIOR OF PAPAYA TAINUNG 1 CULTIVATED IN BRASILIA-DF}

\begin{abstract}
The ripening behavior of papaya fruit Tainung 1 harvested at different development stages through physical-chemical analyses and content of chlorophyll in the fruit skin were evaluated. The analyzed fruits had similar contents of chlorophyll $a$ and $b$, showing difference in the interval from the 63 to the 84 day after fruit set (DAFE). Fruit harvested after 63 DAFE had suitable weight for harvest, however showed an increasing up to 147 DAFE. Fruit length increased up to 147 DAFE, and fruit diameter stabilized at the 126 DAFE. The contents of total soluble solids (SST) oscillated from 2.2 to $10.3^{\circ}$ Brix and the total titration acidity (ATT) varied from 0.038 to $0.077 \%$ of citric acid. The content of chlorophyll $a$ and $b$ decreased as the ripening degree increased, and the suitable harvest stage would be from the 126 DAFE, when the physical characteristics and the contents of SST attained appropriate values for harvest.
\end{abstract}

Index terms: papaya, ripening, chlorophyll.

O mamão é um fruto que apresenta respiração do tipo climatérica, ou seja, ocorre, no fim da fase de maturação, aumento na respiração e depois decréscimo. Durante essa fase, há aumento na produção de etileno, que permite que o fruto amadureça depois de colhido (Ferri, 1985). Um dos principais indicativos do ponto de colheita do mamão é a alteração na cor da casca, mudando de verde para amarela. Essa alteração se deve a uma maior destruição de clorofila, pigmento responsável pela coloração verde e aumento na síntese de xantofila e carotenóides, que conferem uma coloração amarelada (Chitarra \& Chitarra, 1990).

Segundo Award (1993), o mamão apresenta melhor qualidade se colhido quando estiver $30 \%$ amarelo. Mas o ponto de colheita pode variar de acordo com a distância em relação ao mercado consumidor e ao destino do fruto, com o manejo empregado, com a cultivar e com as condições edafoclimáticas predominantes.

No mamão, a mudança na cor da casca é um dos principais parâmetros utilizados na determinação do ponto de colheita. O estudo dos índices de clorofila em frutos de mamão, analisados em diferentes estádios de desenvolvimento, pode trazer respostas mais precisas a respeito do melhor ponto de colheita, de acordo com as condições climáticas que predominam na região.

Além da alteração na cor da casca, a fase de maturação é marcada por mudanças no tamanho, no peso, no teor de sólidos solúveis e na acidez, que são características que indicam o ponto de colheita do fruto. $\mathrm{O}$ trabalho teve como objetivo avaliar a maturação em frutos de mamoeiro 'Tainung 1' colhidos em diferentes estádios de desenvolvimento.

O experimento foi conduzido no Setor de Fruticultura da Estação Experimental de Biologia da Universidade de Brasília, no período de novembro de 2001 a maio de 2002, em uma área experimental de mamão com cinco genótipos, dentre os quais o híbrido Tainung 1. As plantas estavam com 9 meses de idade quando foi iniciado o experimento.

Identificaram-se dez frutos por planta com diâmetros variando de 5 a $6 \mathrm{~cm}$ ( 0 dia após a frutificação efetiva), em 10 diferentes plantas. Após 7 dias, foram identificados novos frutos, sendo esse intervalo mantido durante 3 semanas. Posteriormente, marcaram-se 10 frutos a cada 21 dias até completar 147 dias, quando os primeiros frutos identificados atingiram ponto de colheita (estádio 2). Constatado que os primeiros frutos atingiram o ponto de colheita adotado por grande parte dos produtores de mamões destinados ao mercado interno [estádio 2 , correspondendo a até $25 \%$ da superfície amarela, segundo escala de cores do BRASIL (2000)], todos os demais foram colhidos e levados ao laboratório para análises.

Os frutos foram pesados, determinando seu diâmetro e comprimento, e posteriormente foram retiradas amostras da casca para a determinação do teor de clorofila. Para extração de clorofila da casca, utilizou-se de parte da metodologia de Hiscox \& Israelstam (1979), sendo a restante desenvolvida para o trabalho. Para retirar as amostras de casca, utilizou-se de um perfurador de rolha com diâmetro de $26 \mathrm{~mm}$. De cada fruto, retiraram-se 3 amostras de casca, sendo recortadas em pequenos pedaços e colocadas em tubos de centrífuga, adicionandose $10 \mathrm{ml}$ de dimetilsulfóxido (P.A.). As amostras foram colocadas para reagir em estufa (temp. $65^{\circ} \mathrm{C} / 24$ horas). Retiraram-se $3 \mathrm{ml}$ de cada amostra para leitura de absorbância (comprimentos de onda de 649 e $665 \mathrm{~nm}$ ) em espectrofotômetro digital. Os valores das concentrações de clorofila $a$ e $b$ foram obtidos segundo as equações de Lichtenthaler \& Wellburn (1994).

Dos frutos colhidos, foram retiradas amostras de polpa dos diferentes estádios para a determinação dos teores de sólidos solúveis totais (SST) e acidez titulável total (ATT). Os teores de SST ( ${ }^{\circ}$ Brix) foram determinados através de refratômetro digital e a ATT por titulação

\footnotetext{
${ }^{1}$ (Trabalho 027/2004). Recebido: 11/03/2004. Aceito para publicação: 09/06/2005.

2 Eng. Agr. PhD, Prof. Adjunto IV da Faculdade de Agronomia e Medicina Veterinária (FAV) da Universidade de Brasília (UnB). Campus Universitário Darcy Ribeiro, Cx. P. 04508, CEP. 70.910-970, Brasília-DF. kiyoshi@unb.br.

${ }_{3}^{3}$ Eng. Agr. MSc., Bolsistas DTI/CNPq, FAV/UnB. genifagundes@pop.com.br/atino@unb.br.

${ }^{4}$ Alunos do curso de graduação em Agronomia da FAV da UnB. Bolsitas ITI/CNPq.
} 

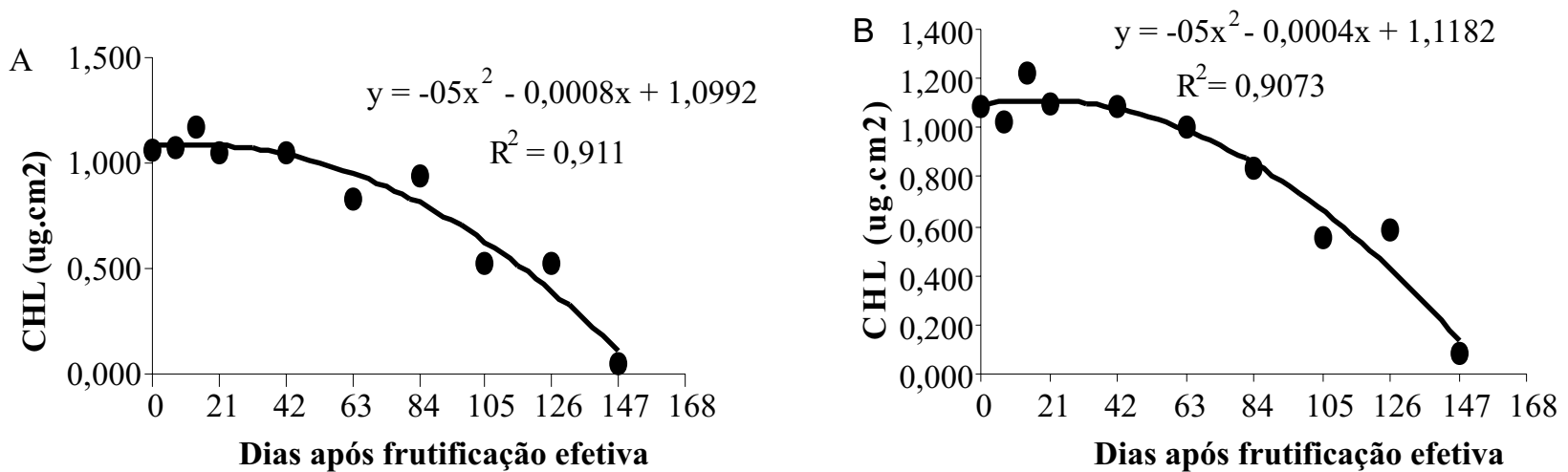

FIGURA 1 - Variação de clorofila $a$ (A) e clorofila $b$ (B) expressa em $u \mathrm{~g} / \mathrm{cm}^{2}$ presentes na casca de mamão Tainung 1, em diferentes estádios de maturação.

com $\mathrm{NaOH}(0,01 \mathrm{~N})$, segundo metodologia proposta pelo Instituto Adolfo Lutz (1974). As médias dos dados obtidos foram calculadas, sendo feitas curvas de regressão representadas através de figuras.

$\mathrm{Na}$ análise de regressão aplicada aos dados dos teores de clorofila $a$ e de clorofila $b$, a equação do tipo quadrática possibilitou a visualização de um comportamento semelhante nos diferentes estádios de maturação (Figura 1). Verificou-se que houve correlação entre os valores médios de clorofila $a$ e $b$, que decresceram conforme o desenvolvimento do fruto. No entanto, observou-se que, nos frutos com 84 e 126 dias após frutificação efetiva (DAFE), houve pequeno aumento no teor médio de clorofila $a$, enquanto para a clorofila $b$ este pico ocorreu nos frutos com 126 DAFE. Os valores médios dos teores de clorofila $a$ e $b$ oscilaram de 1,171 ìg. $\mathrm{cm}^{-2}$ a 0,045 ìg. $\mathrm{cm}^{-2} \mathrm{e} 1,221$ ìg. $\mathrm{cm}^{-2}$ a 0,084 ìg. $\mathrm{cm}^{-2}$, respectivamente. Observou-se que, após o $126^{\circ}$ DAFE, os teores de clorofila $a$ e $b$ caíram de modo significativo, o que poderia significar um alto índice de degradação de clorofila e, ao mesmo tempo, uma alta síntese de carotenóides.

Goldsmith (1980) e Wills et al. (1981), citados por Viegas (1992), explicam que, em alguns tecidos, os carotenóides sintetizados podem ser mascarados pela clorofila durante os primeiros estágios de maturação, porém, quando é iniciada a degradação da clorofila, estes carotenóides tornar-se-iam visíveis.

Como normalmente as frutas atingem o peso e o tamanho máximos antes do amadurecimento, torna-se importante fazer um acompanhamento do crescimento, pois este serve como parâmetro para a determinação do início da maturação. Aplicando a análise de regressão aos dados de peso, comprimento e diâmetro, constatou-se uma representação do tipo cúbica (Figura 2), havendo uma correlação entre estes parâmetros e os estádios de desenvolvimento dos frutos. Todos estes parâmetros físicos apresentaram aumento de acordo com o desenvolvimento do fruto, sendo observada menor variação no comprimento.

O comprimento apresentou pequena variação dos 63 DAFE até o 126 DAFE, já o diâmetro foi a partir do 105 DAFE. O peso variou de $71,4 \mathrm{~g}$ a $1601 \mathrm{~g}$ desde o zero ao 147 DAFE, ocorrendo um aumento de peso até o $147^{\circ} \mathrm{DAFE}$.

Verificou-se que, no $63^{\circ} \mathrm{DAFE}$, os frutos apresentaram médias de peso $(1026 \mathrm{~g})$, comprimento $(22,1 \mathrm{~cm})$ e diâmetro $(10,3 \mathrm{~cm})$ adequados para a colheita, sem, no entanto, terem atingido valores ideais para outras características, como teores de SST $\left(4,4^{\circ}\right.$ Brix $)$, além de apresentarem altos teores de clorofila. Com relação ao peso dos frutos, existe também certa exigência do mercado, sendo que, para frutos do grupo 'Formosa' destinados ao mercado interno, o peso médio pode oscilar entre $800 \mathrm{~g}$ a $1.100 \mathrm{~g}$ (Dantas \& Morales, 1996).

O teor de sólidos solúveis totais (SST) oscilou de 2,2 a 10,3 ${ }^{\circ}$ Brix (Figura 3). Na análise de regressão, os dados de SST foram melhor representados pelo tipo cúbico, observando-se significativo aumento nos teores de SST a partir do $63^{\circ}$ DAFE, estendendo-se até o $126^{\circ}$ DAFE. Tais dados confirmam observações feitas por Calegario (1997), que verificou que a mudança na cor da casca (perda de clorofila) está relacionada ao início de acúmulo de matéria seca e sólidos solúveis totais. Aos $126 \mathrm{DAFE}$, os frutos já apresentavam teores de $\operatorname{SST}\left(10,1^{\circ} \mathrm{Brix}\right)$
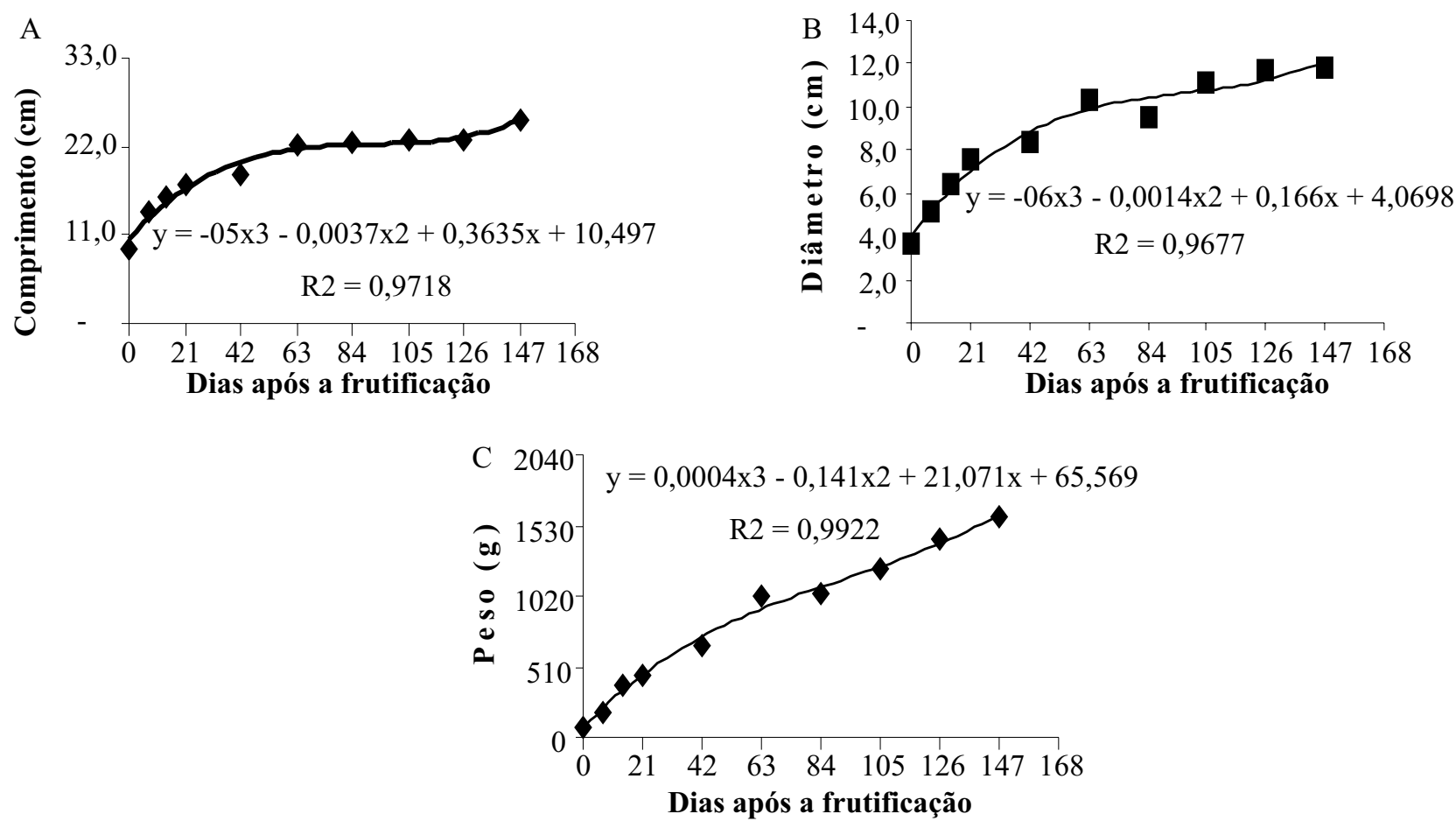

FIGURA 2 - Variação do comprimento (A), diâmetro (B) e peso (C) médio de mamão Tainung 1, em diferentes estádios de maturação. 

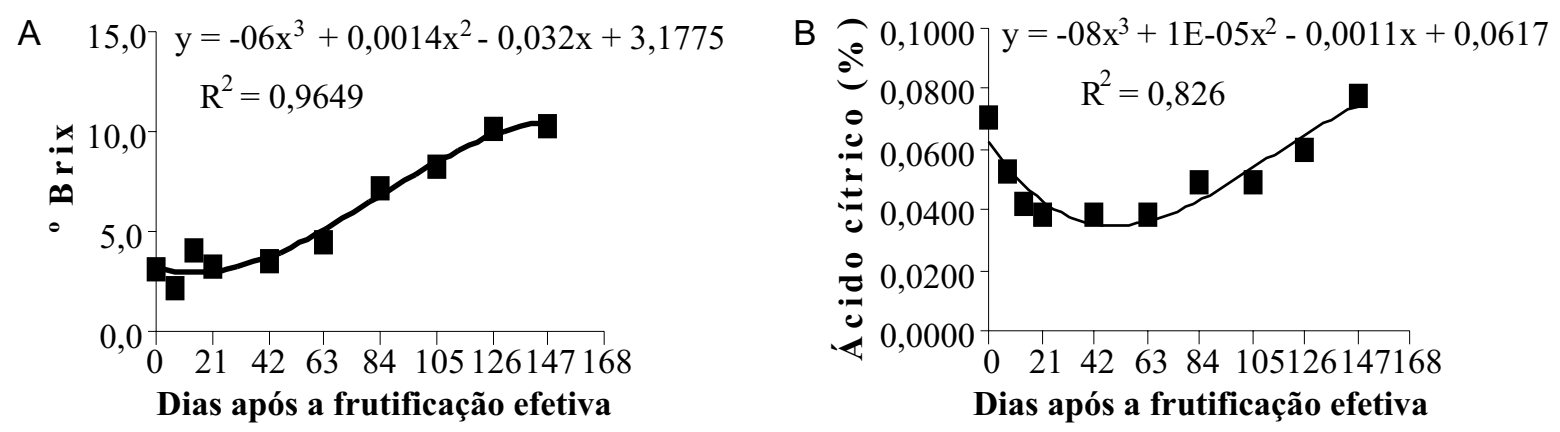

FIGURA 3 - Variação média do teor de sólidos solúveis totais - SST (A) e da acidez titulável total - ATT (B) de mamão Tainung 1, em diferentes estádios de maturação.

dentro do ideal de comercialização para frutos do grupo 'Formosa' destinados ao mercado interno, estando próximos ao intervalo obtido por Fioravanço et al. (1994) em frutos maduros de mamão 'Formosa' ( 8,7 a $10,7^{\circ}$ Brix) produzidos em Porto Alegre-RS. O teor de SST para frutos deste grupo pode variar entre 9,0-12 ${ }^{\circ}$ Brix, segundo dados obtidos em trabalhos realizados por Viegas (1992), Fioravanço et al. (1994) e Fagundes (1999).

A equação de regressão do tipo cúbica para a acidez titulável total (ATT) apresentou variação de 0,038 a $0,077 \%$ de ácido cítrico (Figura 3), similar aos valores médios obtidos por Viegas (1992), em Viçosa-MG, na mesma cultivar. Os valores de ATT decresceram até o $63^{\circ}$ DAFE e logo após houve significativo aumento. Normalmente durante a maturação, os frutos sofrem redução na acidez, porém, em alguns casos, pode haver aumento nos valores com o avanço da maturação (Chitarra \& Chitarra, 1990).

Com base nos valores médios de todos os parâmetros analisados nos frutos colhidos aos 126 DAFE, verificou-se que a colheita pode ser feita a partir deste estádio, pois os valores obtidos estavam dentro do intervalo considerado ideal para comercialização de frutos do grupo 'Formosa' destinados ao mercado interno. É importante sempre avaliar, em conjunto, as principais características que determinam o ponto de colheita (peso, comprimento, cor, SST e outras), sabendo que estão diretamente relacionadas a fatores como condições climáticas, manejo, adubação, tratos culturais, etc., bem como a distância ao mercado consumidor.

Para as condições e época de condução do experimento, concluiu-se que:

- Os teores de clorofila $a$ e $b$ dos frutos decrescem conforme o aumento do grau de maturação.

- O ponto de colheita mais indicado é a partir do $126^{\circ}$ DAFE, por os frutos apresentarem baixos teores de clorofila e características físicas e químicas com valores médios adequados à comercialização.

\section{REFERÊNCIAS}

AWARD, M. Fisiologia pós-colheita em frutos. São Paulo: Nobel, 1993. p.79-80.
BRASIL. Ministério Da Integração Nacional. FrutiSéries 7 - Mamão. Brasília, 2000. 8p.

CHITARRA, M. I. F.; CHITARRA, A. D. Pós-colheita de frutos e hortaliças: fisiologia e manuseio. Lavras-MG: ESAL/FAEPE, 1990. 320p.

CALEGARIO, F. F. Características físicas e químicas do fruto do mamão (Carica papaya L.) em desenvolvimento, 1997. 54f. Dissertação (Mestrado em Agronomia)- Faculdade de Ciências Agrárias e Veterinárias, Universidade de Viçosa-UFV, Viçosa, 1997.

DANTAS, J.L.L.: MORALES, C.F.G. Melhoramento genético do mamoeiro. In: MENDES, L.G.; DANTAS, J.L.L.; MORALES, C.F.G. Mamão no Brasil. Cruz das Almas - BA: EUFBA/EMBRAPACNPMF, 1996.p.93-120.

FAGUNDES, G.R. Aspectos da comercialização do abacaxi, banana e mamão em Brasília-DF - qualidade, perdas e preços, 1999. 158f. Dissertação (Mestrado em Agronomia)- Faculdade de Agronomia e Medicina Veterinária, Universidade de Brasília, Brasília, 1999.

FERRI, M.G. Fisiologia vegetal. 2.ed. São Paulo: EPU, 1985. v.1, 362p.

FIORAVANÇO, J. C.; PAIVA, M. C.; CARVALHO, R. I. N. de; MANICA, I. Características do mamão Formosa comercializado em Porto Alegre de outubro/91 a junho/92. Ciência Rural, Santa Maria-RS, v.24, n.3, p.519-522, 1994.

HISCOX, J.D.; ISRAELSTAM, G.F. A method for the extraction of chlorophyll from leaf tissue without maceration. Canadian Journal of Botany, Otawa, v.57, p.1332-1334, 1979.

INSTITUTO ADOLFO LUTZ. Normas analíticas do Instituto Adolfo Lutz. São Paulo, 1976. v.1,371p.

LICHTENTHALER, H. K.; WELLBURN, A. R. Determinations of total carotenoids and chlorophylls $a$ and $b$ in leaf extracts in different solvents. Biochemical Society Transactions, London, n.11, p. 591$592,1994$.

VIEGAS, P. R. A. Características químicas e físicas do mamão (Carica papaya $\mathrm{L}$.) cultivares "Sunrise solo" e "Formosa" relacionados ao ponto de colheita. 1992. 82f Dissertação (Mestrado em Agronomia)-Faculdade de Ciências Agrárias e Veterinárias, Universidade de Viçosa-UFV, Viçosa, 1992. 